Irish Math. Soc. Bulletin

Number 74, Winter 2014, 27-66

ISSN 0791-5578

\title{
TEACHER CHANGE AND PROJECT MATHS: IMPLICATIONS AND LESSONS LEARNED
}

\author{
SHANNON GUERRERO
}

\begin{abstract}
Because of the similar intents, practices, and expected outcomes of Ireland's Project Maths and the United States' Common Core State Standards for Mathematics, insights into promoting successful adoption of Common Core in the U.S. can be gained by looking at factors that have supported and/or hindered Irish teacher adoption of Project Maths-related content, pedagogy, and assessment. In this paper, a U.S. mathematics educator summarizes her experiences with and insights into Project Math based on a variety of observations, interviews and interactions with various aspects and players involved in Project Maths. This paper highlights observed strengths and limiting structural and personal factors related to teacher change and adoption of Project Maths. The paper then discusses an integrated framework for considering teacher change and concludes with suggested next steps for continued growth and development of Irish math teachers under Project Maths, as well as implications for professional development of teachers adopting Common Core in the United States.
\end{abstract}

\section{INTRODUCTION}

In the early part of 2013, I was hosted by the Center for the Advancement of Science and Mathematics Teaching and Learning (CASTeL) as part of my 3-month sabbatical visit to Ireland. As a mathematics educator and university faculty member engaged in professional development related to Arizona's recent adoption of the Common Core State Standards for Mathematics, I was interested in exploring the professional development of Ireland's post-primary mathematics teachers as part of Project Maths. While my initial insights into Project Maths were provided by an American colleague and predecessor [15], my interactions, observations and interviews with various players in Project Maths provided me with several

2010 Mathematics Subject Classification. 97D40.

Key words and phrases. Mathematics Education.

Received on 23-4-2014; revised 11-7-2014. 
lenses through which to view curriculum, assessment, instruction, and, most importantly for my visit, professional development related to Project Maths.

I approached my experiences in the Irish mathematics education system as an educator who was hoping to garner a few "lessons learned" with respect to continued professional development and teacher change within the context of Project Maths. More specifically, I was hoping to investigate the factors that have both helped and hindered Irish teachers' adoption of the content and pedagogy of Project Maths. While I brought my own research-based and professional experiences to bear in my investigations into Project Maths, I remained cognizant of my own limitations as a visitor within the Irish educational landscape and tried to approach my inquiries with a critical but non-evaluative eye. It is within this context that I hope to contribute to the national dialogue on Project Maths as an outside voice that can provide a fresh perspective on the progress and professional development of Project Maths.

1.1. Context of My Visit. Unlike the centralized governance and funding of schooling in Ireland, the history of education in the United States is one of decentralized governance that places primary authority for schooling on states and individual school districts. Since the 1980's and 1990's, states have taken a more regulatory role over schools by raising education standards, emphasizing state-mandated curriculum requirements, and requiring more frequent standardized testing. Similarly, the federal government has played a larger role in promoting test-driven accountability through acts like No Child Left Behind [23]. Some argue that this decentralized approach to determining individual states' curricula, along with an increased focus on state-wide, nationally mandated testing, has promoted a "national" mathematics curriculum that is unfocused, incoherent and driven by rote computational competence rather than conceptual understanding.

In an effort to build on the foundation laid by individual state standards and create a more focused and coherent curriculum, the National Governors Association Center for Best Practices and the Council of Chief State School Officers released the Common Core State Standards for Mathematics (CCSS-M) in the United States in 2010 [2]. The new content standards called for more depth and less breadth; increased rigor; student centred problem solving; and 
investigative learning [3]. In addition, the Common Core included Standards for Mathematical Practice, a set of process-based standards of mathematical expertise that stressed the practices, dispositions and processes that all mathematics educators should strive to develop within their students (e.g. problem solving, perseverance, reasoning, modeling, making and testing conjectures, etc.). Though not necessarily a national curriculum, the Common Core State Standards for Mathematics were adopted by 45 states and the District of Columbia and is supported by U.S. Department of Education funding initiatives like Race to the Top.

The state of Arizona adopted a modified version of the Common Core State Standards for Mathematics by basing a majority of its mathematics curriculum on the Standards. Since its adoption of Common Core in 2010, Arizona has been holding various types of professional development through state and regional offices to familiarize teachers with the new content, pedagogy and assessment associated with Common Core. Schools were required to adopt the new standards in kindergarten and first grade during the 2011-2012 and 2012-2013 school years, with full implementation at all grade levels by the 2013-2014 academic school year.

Though my role as a professional developer is not directly linked to the statewide efforts to help teachers gain knowledge, application, and integration skills associated with Common Core, I regularly provide grant-based professional development to primary and postprimary mathematics teachers to support increased content knowledge and to help teachers understand and adapt to the content shifts and instructional implications of Common Core at a classroom level. It is in this role that I became aware of Project Maths in early 2012.

As teachers and educators across Arizona were familiarizing themselves with the new content and pedagogical shifts associated with Common Core, I began investigating the instructional and contentbased shifts occurring in the Irish mathematics education system due to Project Maths. Though the contexts in which these two reforms were taking place were decidedly different, I was struck by apparent similarities in intent with respect to the teaching and learning of mathematics in Project Maths and as part of Common Core. Like Common Core, Project Maths included shifts in content, pedagogy 
and assessment that emphasized student understanding of math concepts; increased use of contexts and application; connections to everyday experiences; mathematical investigations; and problem solving [20]. However, unlike Common Core, Project Maths was a nationally developed and mandated curriculum with a meticulously developed and implemented roll-out schedule that included state funding to support curriculum development, project dissemination, and continued professional development of post-primary mathematics teachers in both content and mathematics pedagogy.

Although many facets of Project Maths were intriguing from this side of the pond, I was especially drawn to the continued professional development of Irish mathematics teachers and wondered what type of impact that training was having on classroom practice. Because of the fact that Project Maths was rolling out on a timeline that was three years ahead of Common Core, I was particularly intrigued with the possibility of examining lessons learned from Irish math teachers that could be used to encourage classroom level change for American teachers engaged with Common Core.

\section{Data Collection and Analysis}

Due to my limited time in Ireland, I was unable to implement a large-scale classroom-based study of Project Maths. However, I was able to systematically investigate several facets of Project Maths through a variety of observations, interviews, and interactions with various aspects and players involved in Project Maths. Although I will be the first to admit that this is in no way an empirical study, I do believe it represents a systematic exploration of various aspects of Project Maths.

I began my investigations into Project Maths by reading several reports and papers that provided the impetus and foundation for the development and implementation of Project Maths. Just prior to my arrival, several more documents were released that provided valuable updates on the progress of Project Maths, teacher insights into teaching and learning under Project Maths, and the impact of Project Maths on student learning and motivation. Taken together, these documents provided me with a solid foundation with which to begin thinking about Project Maths and its impact on teacher practice through continued professional development efforts. 
Once I arrived, I began meeting with and interviewing mathematics and mathematics education university faculty throughout Ireland. These meetings served to further my emerging understanding of Project Maths and to help me become familiar with the educational landscape and mathematics education system in Ireland. I attended the one-day Why Math Matters conference ( $8^{\text {th }}$ March 2013) organized by the Higher Education Authority, hosted at the University of Limerick, and designed to take stock and address challenges of practice and policy of maths education in Ireland. I then began meeting with national stakeholders from the National Council for Curriculum and Assessment (NCCA), the Educational Research Center (ERC), the Department of Education and Skills (DES), the National Center for Excellence in Mathematics and Science Teaching and Learning (NCE-MSTL), and the Center for the Advancement of Science and Mathematics Teaching and Learning (CASTeL). Finally, I met with and interviewed the Director of Project Maths; a regional development officer (RDO) for Project Maths; a former Project Maths pilot school teacher and new member of the Project Maths Development Team; and a Project Maths facilitator and Implementation Support Group member.

In order to build on the emerging insights provided by my interviews, conversations, and readings, I then attended two different sessions of Project Maths Workshop 8, which focused on developing student understanding, problem solving, and connections in Calculus. My role at these workshops was that of participant-observer. I sat amongst the participating teachers, collaborating on and completing various activities. I informed the teachers around me of the purpose of my visit and talked informally with several of them on their experiences with and insights into Project Maths. The RDO of these workshops then helped me gain access to a large, representative, interdenominational, mixed gender, socioeconomically diverse national roll-out school in suburban Dublin. I spent 3 days at this school and was able to observe 7 mathematics teachers, some more than once, teach in Project Maths courses ranging from $1^{\text {st }}$ through $6^{\text {th }}$ year and foundation to higher level. At the conclusion of my observations, I interviewed three of the observed teachers on their experiences with Project Maths, its impact on their classroom practice, and factors that have helped or hindered their adoption of the content and pedagogy of Project Maths. As a last foray into the 
maths education landscape of Ireland, I was able to attend a leaving cert higher level grind course during one of my last weekends in Ireland. Though this course did not necessarily lend any insights into Project Maths, it did provide an interesting lens into the high stakes leaving cert culture of mathematics education in Ireland.

Conclusions from my investigations have been based on triangulating "data" from my many varied experiences and interactions with Project Maths. After compiling notes from interviews, observations, informal conversations, readings, and reflections, I looked for emerging common themes and then coded my notes based on those themes. In order to protect the identity of participants and contributors, I am limiting the amount of information provided on leaders, teachers, administrators, faculty and schools that were a part of my investigations.

\section{Strengths of Project Maths}

As a visitor to Ireland and Project Maths, I was struck by the sheer magnitude of resources being leveraged to support the development, implementation, and evaluation of Project Maths. Coming from a country with a decentralized educational establishment, I was impressed with the collaboration and coherence of Project Maths from its inception to its execution. While I am sure there are many more strengths of Project Maths than I am able to cover in a few pages, below are the elements of the project that stood out to me as particularly notable.

3.1. Collaborative Planning of Project Maths. As has been previously documented [15], Project Maths incorporated an unprecedented partnership and collaborative approach between various divisions of the Department of Education and Skills (DES), including the National Council for Curriculum and Assessment (NCCA), the Teacher Education Section (TES), the Maths Inspectorate and the State Exams Commission (SEC). Through an iterative process of content development (by the NCCA), exam modification (by the SEC) and professional development and planning (by the Project Maths Development Team within the TES), Project Maths evolved as a centralized and well-coordinated program that has been exceptionally and singularly focused on the same set of goals and on 
moving the country in the same direction in terms of content, instruction, and student learning. Despite backlash from popular media and some academic and teaching circles, all sectors of the DES involved in Project Maths have remained steadfast in their support, recognition, evaluation and revision of all aspects of Project Maths.

\subsection{Coordinated Implementation of Project Maths. The in-} tentional consequence of such an integrated approach to the development and implementation of Project Maths is that each arm of the DES is delivering a similar message and backing up the products developed by the other arms. In developing course syllabuses, the NCCA worked with SEC, TES, and the math inspectorate to make sure the content and pedagogy of the new syllabuses were understood and endorsed by all parties. The SEC, in turn, developed a new set of exams that incorporated more problem solving, context, and application in order to support the content shifts incorporated in course syllabuses. In developing teacher workshops and in order to deliver a coherent package of professional development in line with the intent of the syllabuses and exams, the Project Maths Development team regularly collaborated with and incorporated suggestions from TES, SEC and NCCA. While one may argue about whether or not these intended shifts have yet been realized, it is apparent that teachers and students are receiving the same message from curriculum, professional development, and exams regarding the content and pedagogy associated with Project Maths.

Such a coordinated and collaborative approach to the development and implementation of Project Maths has allowed for a remarkable coordination and leveraging of resources. Coming from an educational landscape in the United States where innovative programs are often well considered but (seemingly) randomly selected, implemented, and funded based on localized, decentralized decision making, the coordinated effort to fund and support all aspects of Project Maths is especially impressive.

3.3. Continued Profession Development of Teachers. Perhaps one of the strongest elements of Project Maths is its commitment to a long-term professional development model that promotes and encourages teacher change over the course of several years of continued professional development. As part of its development and implementation, Project Maths includes 10 one-day workshops, with two 
workshops per year over the course of five years, designed to introduce teachers to each content strand through pedagogical modeling and hands on explorations within the context of new syllabuses. In addition, teachers are able to attend regional evening content courses to upskill their own content knowledge in specific areas related to the phased in content strands. These courses, though lasting only one day each, are intensely focused on the application of specific strands of content through the modeling of pedagogy associated with the aims of Project Maths.

Considering the scope of content and methodology needing to be addressed in these workshops, the sheer number of participants, and the geographical, logistical and organizational aspects of such a wide scale undertaking, the success of these workshops is laudable. The rate of attendance and satisfaction with the professional development courses, as reported by the Project Maths Development team, speaks for itself. At the time of my visit, over $80 \%$ of Irish maths teachers had completed the first eight pedagogical day courses, with the final two courses being offered during the 2013-2014 academic year. Over 4500 teachers had attended optional evening content courses. Teacher satisfaction rates with both course options remained steady at $99 \%$ approval. In addition to face-to-face course options, teachers have been encouraged to make use of a seemingly endless supply of physical and online resources (cd's, workbooks, sample activities, readings, videos, syllabuses, etc.) through the Project Maths website and other sources of online support.

More recently, additional resources have been allotted to upskill out-of-field teachers through the Professional Diploma in Mathematics for Teaching (http://www.ul.ie/graduateschool/node/347). This program relies on a national consortium of higher education institutions and regional education centers, led by the NCE-MSTL at the University of Limerick, to provide focused subject matter and pedagogical instruction relevant to Project Maths to the approximately $48 \%$ of out-of-field teachers teaching mathematics at post-primary level [22]. Over 350 teachers began this free program in autumn 2012 , and it was expected that an additional 400 teachers would be supported to begin the program in autumn 2013.

Content and pedagogical shifts associated with Project Maths are asking teachers to make significant changes in the way they think about teaching and learning mathematics. The widespread, well 
supported, well attended efforts of the Project Maths Development Team and the Professional Diploma offered through NCE-MSTL are a significant step in the direction of supporting teachers in achieving educational change in mathematics at the post-primary level.

\section{FACtors to Consider}

Despite fairly widespread systemic support for Project Maths, classroom level instructional change has lagged. According to published studies [12], Inspectorate reports, and my own classroom observations, a high proportion of teachers are still engaged in traditional approaches to mathematics teaching and learning. Teachers, by and large, still rely on a didactic approach that includes direct instruction and modeling followed by student imitation of computational procedures with very little variation into problem solving or real world applications. While some teachers, where Project Maths supports their educational philosophies and established educational practices, are making significant progress in adapting to the content and pedagogical shifts associated with Project Maths, post-primary mathematics teaching in Ireland remains largely unchanged, with teaching to the Junior and Leaving Certificate exams a primary focus at all grade levels.

At first glance, the lack of any noticeable change in instruction could be used by detractors to support claims that Project Maths is having no significant impact on mathematics teaching and learning in Ireland. However, in talking with many teachers, it is clear that they generally understand the mission of Project Maths and are desirous of making instructional change, but are hindered in their efforts to change by a variety of internal and external factors. For many teachers, the pedagogy of Project Maths is being adopted in a manner that aligns with their largely traditional approaches with few shifts in fundamental conceptual frameworks about what it means to teach, learn and do mathematics.

Teachers see isolated bits of what they can do but are not truly changing their practices. They are confused. They are clinging to practices that have served them in the past. It's hard for them to blend the old with the new. -Megan, Project Maths leadership team

This type of change-without-change has been described as "first order change" [17] to describe teacher adaptation of innovation to 
fit established norms and practices. First order change forces the innovation to fit into teachers' instructional status quo resulting in little to no true change in instruction. This is quite different to second order change where instruction changes to fit the innovation. Until teachers are given an impetus or motivation to change, innovative practice remains largely unrealized because teachers continue to teach the way they have always taught. While Project Maths is providing that initial impetus through its national dialogue and professional development, until other factors like assessment, curriculum, and national confidence in the system kick in, teacher change will remain sluggish.

This instructional stalemate can be attributed to a number of factors inherent in the sheer scope and scale of Project Maths. Educational change takes time. Some models for change argue that a shift in one year of instruction in one content strand can take over three years to achieve significant instructional change since it can take that long for early concerns to resolve and later ones to emerge [14]. Project Maths is attempting to shift the content and pedagogy of five years of post-primary mathematics instruction across five content strands (i.e. statistics \& probability, geometry \& trigonometry, number, algebra, and functions) with three development levels (i.e. foundation, ordinary, and higher). By the very nature of the enormity of change expected as part of Project Maths, it can be surmised that it may very well be ten to fifteen years before large scale significant instructional change is observed. As one Project Maths team leader acknowledged, "This is going to take 10 years and teachers are going to have to keep at it."

The difficulties with the roll-out schedule that incorporated shifts in $1^{\text {st }}$ and $5^{t h}$ year at the onset of Project Maths have been widely publicized and detailed in several other publications [4, 9, 15]. While such a roll-out schedule undoubtedly created difficulties and confusion for both teachers and students, there is no assurance that other roll-out paradigms would have alleviated these problems. Any rollout paradigm would have been disruptive and cause for considerable change for both teachers and students. An in depth discussion on the pros and cons of the chosen versus alternative roll-out plans is beyond the scope of this paper. However, it should be acknowledged that in addition to impacting teaching and learning, the phased in approach and associated professional development plan resulted in 
a gulf between the immediate instructional and planning needs of many teachers and the professional development services provided. For many teachers, if the content strand focus of each workshop was not immediately applicable, the training resources ended up on their shelves with very little immediate use or applicability. By their own admission, it has been hard for many teachers to see the "big picture" of Project Maths, with the many and varied connections between content, pedagogy, training, and classroom practice, while in the midst of their five years of workshop-based professional development. For many Phase I teachers involved with the pilot implementation of Project Maths, it was not until they had completed all 5 years of workshops and training that they were able to "see" the more holistic intent, cohesiveness, and methodology of Project Maths. As such, it will take time for national roll-out teachers to understand, experience, synthesize, and apply the connections between content strands, grade levels, and instructional shifts needed for Project Maths.

Having acknowledged that very little change has occurred to date, it would be hasty to assume Project Maths will have no long term impact on mathematics teaching and learning. The twice-a-year pedagogical workshops, evening content courses, and Teacher Professional Diploma program are all laying a foundation upon which future change and further growth will occur. Having talked with many teachers, participated in Project Maths workshops, and witnessed the singularly supported and focused Project Maths commitment by various arms of the TES, I fully expect Project Maths to have a long term impact on teacher content knowledge, classroom practice, and student engagement with mathematics in Ireland. However, as Project Maths moves from its second phase focused on intensive professional development at a national level to a third phase focused on supporting sustained instructional shifts, there are several factors, both internal and external, personal and structural, that must be considered and addressed.

These factors are not criticisms of Irish math teachers or of the structure of the Irish mathematics education system. They are factors that I discussed with various players in Project Maths, read about in various articles and reports, and observed through my own interactions with various facets of Project Maths. In discussing these 
factors, I realize that some may be directly addressed and/or rectified, while others may just need to be considered as factors that are influencing teachers' adoption of Project Maths. This discussion is not necessarily a call to change, but may be seen as an outsider's perspective of external (or structural) and internal (or personal) barriers that need to be acknowledged and considered as Project Maths moves forward into its next phase of implementation. (It must be noted that the following discussion is, by no means, exhaustive. Rather, it represents the prevalent issues I witnessed and experienced during my short visit and immersion in Project Maths.)

4.1. Structural (External) Factors. There are three main categories of external factors that I see playing a role in the lag between the aims and professional development of Project Maths and actual classroom level instructional change. These "structural" factors are inherent in the educational landscape and exist beyond the teacher, yet they influence teacher practice and ability or willingness to change. None of these factors, in and of themselves, will prevent the success of Project Maths, but each should be considered a structural element of the mathematics education landscape in Ireland that is influencing Project Maths' ability to promote instructional change.

4.1.1. Time. Anyone who has taught or talked with teachers knows that lack of time is the universal quandary of a teacher's life. In the course of a normal teacher's day, there never seems to be enough time to teach, plan, assess, grade, collaborate, or reflect. When being asked to participate in professional development and then devote time to new planning and teaching associated with instructional change, time becomes even more of an issue. For teachers of Project Maths, issues related to time are especially challenging when considered with respect to timetables, time for reflective practice, and time for dedicated departmental interactions.

The very nature of schooling in Ireland, with an emphasis on a wide variety of content areas, has resulted in relatively short periods that limit teachers' abilities to promote student-centred approaches to learning. As has been discussed in other reports [15, 20], current timetabling does not necessarily support the instructional and learning needs of teachers or students. With many periods lasting only 30 to 40 minutes [15, 20], most teachers admit to having only 
15 to 20 minutes of instructional time once logistical elements of instruction like attendance and homework have been attended to. Left with such a short amount of time in which to teach a concept, many teachers feel forced to resort to the ever-efficient method of direct instruction. Add to that the effect of sometimes meeting only four of the five instructional days of the week, and some teachers see a given class for less than a total of two and a half hours per week . In contrast, students in the United States typically spend 45 to 55 minutes in a single period, meeting for math every day of the week, for a total of over 4 hours of math instruction. When faced with a seemingly longer syllabus as a result of content shifts in Project Maths, teachers simply do not feel they have the time to focus on student-centred approaches that promote conceptual understanding, problem solving or real world application. [4, 20]

There's not enough time to get through the syllabus. Not enough time to teach all the content of the course, especially when you take into account the new pedagogy that takes more time in the teaching. -Cian, maths teacher $\& 5$ department chair

While short instructional periods for maths has an obviously detrimental impact on teacher instruction and student engagement with content, there is an even more alarming and indirect consequence of timetabling on teacher practice and reflection. Planning for effective student-centred instruction takes a substantial amount of time to reflect, arrange, prepare, and envision. Teachers that I observed in Ireland taught up to 8 or 9 different classes in a single day, within and outside of mathematics, and never repeated the same course or grade level from one period to the next. Though a bit extreme, it is my understanding that this arrangement of teacher instructional scheduling is not outside the realm of normal practice at most schools. [19] Even with adequate resources and a well-defined and supported curriculum, it would be nearly impossible for teachers to effectively plan for 9 different classes 5 days a week. The result is the type of first order change previously discussed where teachers must adapt Project Maths to their existing and largely traditional teaching style and resources since there is no conceivable way to effectively contemplate or plan for that many different classes in a single week. As one teacher put it, "It is amazingly difficult to plan 
and prep for nine student-centred, problem solving based lessons per day."

Because of timetabling practices that sometimes focus on grade level, content strand, or other such normalized factors, teachers often end up teaching a different grade level and a different content strand every period without ever repeating a single course or grade level during the day. In contrast, when I was a secondary teacher in the United States, I taught (as an example) Algebra I for three periods and Geometry for two periods every day of the week. Not only did I teach fewer, longer periods, but after teaching my first period of Algebra, I was able to quickly reflect on what went well in terms of both content and pedagogy, and what needed to be modified for the next class. The teachers I observed in Ireland were allowed no such time to reflect on practice, let alone make subtle changes for reteaching later in the day. They simply moved on to the next class with very little thought about the nuances of content or pedagogy just experienced by both them and their students. By the end of the day, teachers had taught up to 8 or 9 different classes and had neither the memory nor the capacity to reflect back on the planning, content, and instruction for any single period or class.

Reflective practice is an elemental part of good teaching, especially when asking teachers to engage in substantial shifts in the way they think about teaching and learning mathematics. As teachers try new approaches, there are going to be ups and downs, methods that work well, and others that need tweaking. Reflecting on planning, instructional shifts, and student learning experiences is an important part of the change process and one that is limited for Irish teachers by the very nature of timetabling. With far too many different classes to plan for and far too little time for immediate reflection or change, teachers are left in a frenzied limbo of instructional status quo. By the end of the day, teachers are so inundated with the pedagogical particulars of each class, each student, and each lesson that they are unable to remember or reflect on what they just taught let alone what they taught eight periods ago.

One school-based structure that could help ease individual teacher's burdens, in terms of collegial support, collaborative reflection, and systemic change, is the mathematics department unit. However, for many post-primary schools, there is very little dedicated time for content departments to meet and truly collaborate on content, 
planning and instruction [19]. The mathematics departments of most teachers I talked to met only a few times a year, if at all. Undoubtedly, secondary teachers are a busy group with their many and varied extracurricular activities, involvements, and commitments. Timetabling further complicates the matter with teachers on or off campus at various times during the day and week. However, as teachers engage in this change process, it is important for them to be part of a community of practice, where they can talk, reflect and share with other teachers engaged in the same change process.

What does a functioning maths department look like? It's not a gripe session. . not a cover your ass session to get ready for the inspector... not time to talk about what chapter to cover for the common final. We need to spend time talking about content... how we could teach something... share ideas. But, there's no history or culture of that here. - Conor, Project Maths development team member $\&$ former maths teacher Individuals talk and share ideas but, as a department, we don't meet to talk about maths or pedagogy. Our meetings are usually about school issues and policies. -Cloe, maths teacher

4.1.2. Textbooks. Because of the close interplay between curriculum and instruction, a considerable shift in instruction must be accompanied by curriculum that supports such change. While the Project Maths Development Team has done a commendable job of providing teachers with a plethora of activities and resources through their training and online/print resources, teachers inevitably rely on their textbooks as significant determiners of the content of their instruction. While analysis of textbooks was not part of my visit to math classrooms in Ireland, recent research [4, 9, 15, 18] and discussions with teachers highlight the disconnect between widely adopted texts and the intent of Project Maths.

Teachers teach from textbooks that are very predictable and serve their traditional approaches well. - Megan, Project Maths leadership team

While textbooks remain largely traditional and procedural in their approach, teachers are being asked to make significant shifts toward problem solving and understanding in their teaching. As such, 
teachers are compelled to individually integrate and synthesize their traditional classroom texts with Project Maths syllabuses, Project Maths teaching and learning plans, Project Maths instructional resources, and their own ideas and experiences in mathematics teaching and learning. The result is that many teachers are trying isolated bits of Project Maths resources, but most teachers are not fully integrating Project Maths content or pedagogy into their teaching. Even where teachers are willing to incorporate a substantial amount of Project Maths materials, they still feel pressure to use texts because of the value "the system," especially students, places on texts. While effective teachers will use multiple sources in their planning and instruction, Irish teachers currently lack a single foundational resource from which to plan, assess, and create instructional experiences that align with the intent of Project Maths. [19]

Planning and resources are difficult. I try to use as much stuff from Project Maths that I can, but it's not super friendly for use in math classes. We're told that these materials are not classroom ready. Textbooks are. They're very traditional, though. -Sarah, maths teacher

Am I not a good teacher for using the book? Sometimes I need to show them how to do something and have them practice. It's not the best, but it's all I've got. -Cloe, maths teacher

4.1.3. Certificate Examinations. As with other American researchers who have visited Ireland before me [15], I was struck by the pervasiveness of the certificate exams and the hold they have on the entire educational system in Ireland. In almost every discussion, reading and observation I conducted, certificate exams, especially the Leaving Cert, held sway in driving content and pedagogy in the mathematics classroom. While a discussion on the merits of an exam-driven system is beyond the scope of this article, it must be acknowledged that the Leaving Cert Exam drives mathematics education in Ireland [1, 15]. As such, Project Maths is attempting to find a balance between the pervasiveness of "teaching to the test" and teaching mathematics for understanding and application. However, striking that balance in the midst of a heavily focused testing 
culture, and helping students and parents understand that each of these aims is not mutually exclusive, remains a difficulty.

I'm not sure if our exam driven culture fits with the philosophy of Project Maths. Kids aren't going to say thanks for teaching me, they're going to say thanks for helping me get an A. How can we not study for 3 to 4 months when we are reviewing for 2 or 3 years of content for the exam? - Cian, maths teacher 8 department chair

From the students' perspective my job is to prepare them to do well on the exam. From the parents' perspective a teacher needs to be done so they can help their students review old exams and grading schemes. Their job may not necessarily look like this under Project Maths. -Megan, Project Maths development team

While the SEC has done a commendable job being adaptive by responding to the content and pedagogical shifts of Project Maths, the Leaving Cert exam still remains a bit of a moving target for many teachers and students [4]. As each subsequent strand has rolled out over the years, the cert exams have blended old and new content and problem solving applications.

Exam papers are the worst of the whole lot. We haven't had enough of the new type of questions to help students prep. - Cloe, maths teacher

With the final roll-out of Strand 5 during the 2012-2013 academic year and the Leaving Cert exam reflecting fully implemented Project Maths syllabuses by June 2014, teachers will move beyond transitional glimpses of Project Maths reflected in the Leaving Cert Exam toward a more holistic understanding of the application and assessment of Project Maths. It could be expected that, with time, teachers will begin to settle into the new approach to content and problem solving reflected in the exams. Parents, students, and teachers need to become more comfortable and experienced with questions and expected responses that focus more on meaning and explanation rather than a singular focus on a correct answer. Experience, exposure, and classroom modeling will similarly help address concerns related to mathematical literacy on the exams. Through the revision of transitional exams and problems, the SEC will also gain 
more experience in the writing and posing of items that truly assess student understanding of content in authentic ways. Changes such as reducing the predictability of content and ordering of exam questions, while controversial in bucking the established cultural norms of testing in Ireland, are similar improvements in promoting authentic problem solving that will become normalized as teachers and students become more familiar with Project Maths content and assessment.

A final external cultural aspect of testing in Ireland that needs to be contended with is the emphasis on revision. There is, in fact, a deeply engrained culture (and lucrative industry) that assumes the last 3 or 4 months of third and sixth year need to be spent in revision. Parents and students feel that teachers are not doing their job well if they have not finished teaching third and sixth year by February so that the revision process can begin.

The cultural influence is great. Teachers will be done teaching by February so that they can spend four months revising. There is tremendous pressure on teachers to finish early so they can spend time practicing exam papers. -Conor, Project Maths development team member $\&$ former maths teacher

As such, a course that is expected to take two (Leaving Cert) or three (Junior Cert) years to teach, is expected to be taught in a fraction of that time. Even in courses where new instructional and learning approaches are utilized, as exams approach, teachers and students feel the need to revert to more traditional approaches for exam preparation and learning [19]. As Project Maths continues to evolve, a culture so singularly focused on exam success and preparation needs to be balanced with a focus on learning for understanding. In some respects, this becomes an issue of helping parents, students, and teachers understand that a pedagogical approach more focused on developing deep conceptual understanding and application of mathematics will reduce the need for procedural revision. Engendering confidence in the content and pedagogy of Project Maths to promote meaningful learning will take time, experience, and continual promotion of the benefits of Project Maths to all parties involved.

4.2. Personal (Internal) Factors. In addition to the external factors discussed above, there are three main categories of internal 
factors that I see as playing a role in hampering teachers' ability and willingness to adopt pedagogical shifts associated with Project Maths. Internal factors are deeply rooted personal beliefs about teaching and learning and are often more difficult to overcome than external, structural factors [8]. Helping teachers alter their internal beliefs and understanding of Project Maths, the nature of mathematics, and what it means to "do" mathematics will be crucial to the success of Project Maths. Based on my discussions, observations, and interviews, I feel that Irish teachers, by and large, lack confidence in their own content knowledge, in the pedagogy of Project Maths, and in the content and alignment of Project Maths with national assessments. For some teachers, increasing confidence in all areas may simply involve allowing them the time to experience and engage with Project Maths content and pedagogy; for others, a more concerted effort of continued content development and site based support may be the answer.

4.2.1. Confidence in Content Knowledge. With anywhere from $33 \%$ to $48 \%$ of Irish math teachers being considered "out of field" [4, 22], it is no wonder that a lack of confidence is a large impediment to authentic implementation of Project Maths.

If teachers don't understand the maths first, then they can't implement the pedagogy well. Teachers with weak background will hide behind the textbooks. You can't deliver a good lesson if you don't understand the mathematics. If teachers have confidence in their maths knowledge they'll ask the open ended questions, go there, and be able to explore. -Conal, Inspectorate

For those who are qualified to teach mathematics and should easily adapt to content changes and additions, Project Maths is presenting them with content they have never seen or have not seen in many years.

Familiarity with the new content scares me the most.

- Cloe, maths teacher

Interpreting the syllabus is also an area of great concern for teachers. Shifts in detail and language remain problematic for some teachers, especially when it comes to making connections between the content of the syllabus and how that gets enacted in the classroom. 
In addition to introducing unfamiliar content, Project Maths is expecting teachers to make more concerted connections across content strands and between grade levels. These types of connections require depth of content knowledge and proficiency in teaching mathematics for understanding that many Irish maths teachers are unfamiliar with at this time. While the evening Project Maths content courses and Professional Diploma are going a long way toward addressing teachers' lack of content knowledge, for many teachers the act of teaching will go a long way toward helping them become more familiar and confident with the content of Project Maths. As recent reports have argued [19], immersion in teaching under the revised syllabus will help teachers understand their content better, as well as understand connections between concepts.

4.2.2. Confidence in Pedagogy of Project Maths. Project Maths is asking teachers to completely rethink and confront their established norms, assumptions, and expectations regarding mathematics teaching and learning. But many teachers lack confidence in their ability to teach mathematics in a student-centred, investigative way [4]. This lack of confidence manifests itself in concerns about time time to teach in a student-centred, investigative way; time to get through a (perceived) longer syllabus; and time to finish months early in order to begin revision.

Teachers race through the two years for leaving cert program in order to leave time for revision during the last four months. We need to get over this reliance on revision and teach for understanding over the whole two years. Teachers, parents and students need to buy into the system and trust the pedagogy a little more. -Liam, NCE-MSTL

Besides not trusting the timing of Project Maths content and pedagogy, teachers do not really trust the pedagogy of Project Maths to teach students for long term understanding and success. While it may take more time than direct instruction, a problem-based approach to mathematics has the potential to connect content and promote conceptual understanding. Teachers, though, see a trade off in teaching for understanding versus the loss of being able to cover every aspect of the text. 
It takes too much time to teach this way and then I fall behind where I need to be. -Sarah, maths teacher

In addition, a student-centred approach runs counter to an instructional culture, reinforced by parents and students, where teaching mathematics means "telling how to do" mathematics. Project Maths is asking all players (i.e. parents, students and teachers) to deal with the dissonance of transforming long established norms and assumptions about what it means to do mathematics. Along with procedural competency, "doing maths" now involves interpretation, problem solving, understanding contexts, quantitative reasoning, and applying mathematical models in non-routine ways. As with building confidence in content knowledge, many teachers may simply need well-supported experience with and immersion in new pedagogical approaches.

We have a tendency to give up new methodologies too easily. We need practice teaching out of our comfort zone. -Cian, maths teacher $\&$ department chair

Learning a new methodology is not easy. Understanding the nuances of when to question, how to pose a problem, when to allow students to discuss a problem, and when to pull them in for redirection takes practice. Through classroom-based experiences, collaboration, and reflective practice, teachers will be allowed to discover for themselves which pedagogical approaches are most appropriate for which situations and how their pedagogical decisions can be leveraged to promote connections between and within mathematics.

4.2.3. Confidence in Content and Assessment. While some would argue that Ireland needs to shift to an "exam led" culture over its current "exam driven" educational culture, it remains a fact that the Leaving Cert exam dictates what happens in the mathematics classroom, in terms of both content and pedagogy. The stakes for shifting long-established norms for content and pedagogy remain high. The result is that, in order to make sure their students have all the content they could possibly need for the exam, teachers admit that they try to teach all of the old content along with the new.

Rather than trusting a problem-solving approach to teach students how to deal with unfamiliar content and applications of mathematics in an exam-based situation, teachers are trying to prepare their students for every eventuality. This approach actually runs counter 
to the intent of shifts that have been made in both the Leaving Cert and Junior Cert that ask students to solve problems that, while supported by Project Maths syllabuses, may not have been explicitly linked to a specific learning outcome. We see the result of this disconnect in the annual backlash regarding wording, phrasing, and specific content of annual state certificate exams. Students and teachers are still adjusting to a problem solving based approach to assessment that removes all previously guaranteed elements of predictability and choice [4].

The predictability of the old papers is still causing problems since teachers are trying to predict new exams and teach everything. - Megan, Project Maths leadership team

Because the exams have been seen as a bit of a moving target, the discomfort and lack of confidence in connections between Project Maths content and pedagogy and the exams themselves is understandable.

We're still caught up in these transition exams and are unsure how these will eventually look, what will be on them. -Cian, maths teacher $\&$ department chair

It should be expected, too, that the SEC has needed time to adjust to new content and assessment-related norms and expectations in trying to create national exams and specific questions that delve deeply into student conceptual understanding, problem solving, and mathematical reasoning. Ambiguous questions, mathematically invalid solutions, and unclear expectations, though rare and unfortunate, are to be expected in this time of flux. Flexible rubrics that emphasize process over product are commendable. Ridding the country of exams where teachers and students universally know to avoid problem number six and know exactly which formula to use for problem number one is laudable. However, as with the content and pedagogy of Project Maths, teachers and students need time to adjust to these new exam-related norms, expectations, and problem situations. Now that all strands of Project Maths have rolled out, it can be assumed that the Junior Cert and Leaving Cert exams will more closely align with the content and problem solving approach of Project Maths. And, as frequently acknowledged throughout my many visits and interviews, once the exam becomes more predictable (in terms of methodology, if not content), then 
teachers will have the confidence in "the system" to begin making steps toward instructional change.

If assessment changes to reflect student understanding then that will force teachers to change. Exams will ultimately drive classroom practice. - Conor, Project Maths development team member $\&$ former maths teacher

As can be seen from the above discussions, despite (or perhaps because of) a tremendous investment in continued professional development, teachers still have deeply entrenched concerns about Project Maths content, pedagogy, syllabuses, and assessment. The educational context in which these concerns arise has several structural factors further contributing to the difficulty of classroom level adoption of Project Maths. As Project Maths moves forward, it will need to address external, structural factors related to time, resources, and certs while continuing to support teachers to experience classroom-level success in order to help them overcome lack of confidence in their own content knowledge, the content and pedagogy of Project Maths, and national assessment paradigms.

4.3. Addressing Factors Limiting Change. Overlying each of the factors discussed above is the cyclical nature of change and an understanding that huge shifts in culture and long-established practice will take time. In some sense, external (or structural) factors may be easier to address than internal (or personal) factors.

External factors, such as textbooks and certs, are already being addressed as a natural extension of time and experience with Project Maths. Issues related to the structure and content of textbooks were raised by researchers [18] and a national dialogue has already begun around this issue. With the final rollout of Strand 5, questions about the content and structure of the Junior and Leaving Certs are expected to wane as exam writers become more experienced at developing fair and accurate assessments and students and teachers become more familiar with exam structures. With time and continued support, teachers will be better able to incorporate content and pedagogy that will prepare students for these types of evaluative experiences. Similarly, teachers and students can focus on modeling and developing the mathematical literacy skills needed to succeed on these exam questions. Perhaps the most pervasive and 
difficult external factor to address will be time. Structural issues related to short periods, limited instructional time, overtaxed teachers with too many periods and too many courses to prep for, and an educational configuration that systematically limits collegiality and reflective practice need to be addressed at national and local levels. While it is not realistic to overhaul the entire structure and timing of post-primary schooling and scheduling, a structured, systematic way to support embedded reflection, teacher collaboration, and focused planning must become part of the mathematics educational culture in Ireland if Project Maths is to ultimately change teaching and learning.

Internal factors related to teachers' lack of confidence in content, pedagogy, and assessment of Project Maths will largely be a matter of continued support and immersion in classroom contexts and reflective practice. This is not to say that teachers' comfort and confidence will simply increase with no further intervention. Rather, a continued focus on instructional growth with external support and resources, along with contextualized classroom-based experiences, will help teachers become more comfortable with and confident in the pedagogical and content-based shifts associated with Project Maths.

\section{Contextualizing Teacher Change}

While looking at barriers to teacher adoption of Project Maths may seem like a "deficit model" approach to teacher change, it is important to understand the context of mathematics teaching in Ireland and the factors that may be limiting change for some teachers. Obviously, teachers, teacher experiences, and teacher adoption of Project Maths vary from person to person and school to school. Throughout my entire Irish experience, teachers, by and large, exhibited thoughtfulness and effort in trying to understand the intent and approach of Project Maths and demonstrated genuine concern for the potential impact of Project Maths on their students. In trying to understand the various internal and external factors discussed above, this section will incorporate two frameworks, one related to the interaction of beliefs, practice and learning outcomes, and the other related to the developmental phases teachers go through as part of the change process. The use of such frameworks allows for examination of and informed decision making related to teacher 
change in Ireland in the context of documented themes and processes from existing research. Inherent in each of these frameworks is the understanding that continued professional development and support, aimed specifically at promoting authentic integration of Project Maths at an individual and classroom level, will be necessary in order to continue building upon the efforts of the national rollout and intensive professional development of Irish maths teachers to date.

As has been highlighted throughout this paper, changing teachers' beliefs about the nature of mathematics teaching and learning is a gradual and difficult process [10]. As they engage in the change process, it is expected that teachers will have various concerns and levels of engagement along the way. There are many paradigms, theories and frameworks with which to think about teacher change and with which to describe teachers' progress. Some [10] argue that shifts in teacher practice and student achievement need to occur before, and will ultimately result in, shifts in teachers' beliefs and attitudes. Simply put, “... significant change in teachers' attitudes and beliefs occurs primarily after they gain evidence of improvements in student learning." [10, p. 383] Other models, like the Concerns Based Adoption Model (CBAM) [11], are built upon an assumption that an innovation must first fit with individuals' beliefs and perceptions so that it can be incorporated into the operating principles of teachers. In other words, teachers must believe in the aims and philosophy of the instructional change model in order to act upon and internalize its basic tenets and instructional behaviors [17]. As a third option, teacher change models that focus on motivation contend that teachers must have dissatisfaction with their current practice and student outcomes in order to be motivated to engage in the change process. For these teachers, a desire to change stems directly from the belief that current practice is lacking and something needs to change in order to improve student learning.

An epistemological debate on the merits of various instructional change theories is beyond the scope of this paper. In fact, I believe none of these theories are mutually exclusive and that each may actually draw on the other. Though it seems a bit circular, change is a learning process in which teachers must engage in order to change. As such, changes in teachers' beliefs about the teaching and learning of mathematics influences their instructional practice which impacts 
student outcomes which, in turn, influences teachers' beliefs and promotes changes in practices (see figure 1). This more circular approach acknowledges that teachers' beliefs and practices are not static and continually influence the other.

Changes in teachers'

beliefs \& attitudes
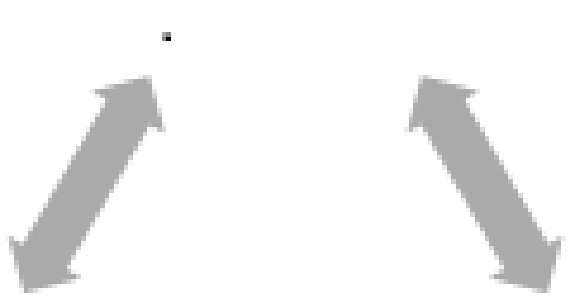

Changes in teachers classroom practices

FiguRE 1. An integrated model of teacher change

Why is this important? Project Maths has invested a considerable amount of time and energy in continued professional development geared at changing teachers' classroom practices so that instruction will positively impact student learning outcomes, in both Leaving Certs and beyond. Though not explicitly addressed, it is assumed that teachers will likewise shift their beliefs by simply engaging in related continued professional development experiences and through immersion with Project Maths within the classroom. While true that some shift in attitudes and beliefs will occur as teachers begin to see a positive impact on student learning, classroom engagement, and performance on exams, it is apparent by the extensive lack of confidence in various elements of Project Maths and themselves (as discussed above) that teachers need much more than simple exposure or immersion to overcome some of these more internally driven concerns. Project Maths includes a much more fundamental shift in 
the way teachers think about the teaching and learning of mathematics than simply throwing in a hands-on activity here and there. Though teachers have been provided with initial skills and resources with which to begin making that shift, support throughout the next phase of adoption of Project Maths and change will be crucial.

Continued facilitation and encouraged collaboration at the school site level will provide teachers with a means of further refining their instructional practice through iterations of trying new approaches, sharing insights with colleagues, and trying again. Of course, the ironic potential consequence of this circular model of change is that teachers need to implement Project Maths with fidelity in order to see an impact on student learning that will drive changes in beliefs about the teaching and learning of math that will drive further changes in practice. But, if teachers are adopting Project Maths to fit into their largely traditional approaches then they will not see the expected impact on student learning and will not shift beliefs to align with a more conceptual, student-centred approach to mathematics teaching and learning, and will therefore not make authentic changes in belief or practice. In order to confront the potential for such a first order adoption of Project Maths, regional and site based leaders will need to play a continued role in supporting teachers throughout this change process.

Several models for change identify development phases individuals progress through as they become more aware of, engage in, accept and apply an educational innovation. These stages are fairly predictable, gradual, and common across models. For example, CBAM [11] identifies seven phases that include awareness, informational, personal, management, consequence, collaboration, and refocusing. Madinach and Cline [16] described a model where teachers progressed through stages of survival, mastery, impact and innovation. Duffy's [6] 9-point development model similarly progresses from early stages of confusion and trying out, to mid level stages of modeling and making sense, to later stages of creation and invention. When applied to the content and pedagogical shifts associated with Project Maths, I argue that we can analyze the changes Irish teachers are making, in the context of the integrated model of teacher change discussed above, according to three general phases that incorporate elements and general progressions outlined by these and 
other developmental phase change theories (see figure 2). In broadest terms, the first phase includes a focus on self whereby teachers are becoming aware of the innovation and thinking about its impact on their current practice. The second deals with classroom level impact, in terms of both content and pedagogy, and culminates with a focus on the impact of change on student learning. The final phase, which is realized several years down the road, is the result of authentic change and results in innovating practice and concerns related to broader educational impacts. By examining these three phases of developmental concern with an understanding that teachers are simultaneously and iteratively shifting practice, attitudes, and beliefs as they see impact of changes on student engagement, learning and achievement, then we can begin to contextualize the progress Irish teachers have made to date with adopting the pedagogical and content shifts associated with Project Maths.

\begin{tabular}{|c|c|}
\hline & Devel opmental Concern Three Phase Model \\
\hline \multirow[b]{2}{*}{ 目 } & Impact on Broader Educational Community \\
\hline & Original Innovation \\
\hline \multirow{3}{*}{ 竎 } & Impact on S tudent Achievement \\
\hline & Impact of Project Maths Instruction on S tudent Leaming \\
\hline & Logistics of Class room Implementation of Project Maths \\
\hline \multirow{2}{*}{ 郎 } & Impact of Project Maths on Es tablished Teaching Practice \\
\hline & Aw areness and Interaction with Project Maths materials \\
\hline
\end{tabular}

Figure 2. A three phase developmental model of concern

Because of the intensive continued professional development efforts as part of the national rollout of Project Maths, teachers in Ireland are certainly aware of the scope and intent of Project Maths and have had ample opportunity to be exposed to and interact with the content and pedagogy of Project Maths. Most teachers, then, have progressed to the latter stages of Phase I or the initial stages of Phase II. Almost all of the teachers I interacted with were concerned with the impact Project Maths would have on their own practice (i.e. how they will incorporate it into their current practice) and the classroom level logistics of implementing instructional 
and content related shifts associated with Project Maths (i.e. how to rearrange timing of activities, progression of content, etc.). It should be noted that expressing concerns about various phases do not necessarily indicate action. Although teachers are thinking about the logistics of classroom implementation, they are still developing the skills with which to authentically implement and think holistically about Project Maths across grade levels and content areas. We see evidence of teachers' progression toward classroom related impacts and implementation via stated concerns about the personal (e.g. confidence in content knowledge, pedagogy, and content) and structural (e.g. time, textbooks, and certs) factors discussed previously. It is interesting to note that concerns about performance on Junior and Leaving Certs is included in concerns about established teaching practice rather than student achievement because teachers are focused on the potential impact of instruction on cert performance rather than any true indication of concern about longer term achievement, understanding, and learning in mathematics. This cannot be a surprise given the exam-driven educational culture in Ireland and the very high stakes involved for all players.

While teachers have progressed through stages related to instructional impact and implementation of Project Maths, they have not fully progressed into dealing with concerns related to the impact of instructional shifts on student engagement with mathematics and long term achievement. By and large, teachers are exploring various resources, scrutinizing new syllabuses, and dabbling in elements of Project Maths but are largely relying on established practice and resources. Very few teachers exhibited reflection on or understanding of the potential impact of instructional shifts on student learning and long term conceptual understanding of mathematics. True change and full implementation of Project Maths will occur when teachers have moved through the phases of development beyond concerns about national exams, textbooks, syllabuses, and impact on instruction, to concerns about the impact of their pedagogical decisions on student learning beyond achievement on exams. True shifts in beliefs and practice will be realized when teachers become committed to improving the student learning experience and believe this will occur through authentic adoption of Project Maths. Part of this shift will occur through continued exposure to and classroom experience with various elements of Project Maths. However, a true shift 
to impact and innovation will occur with continued support and resources aimed at classroom level implementation of Project Maths. Through sustained support and experience, new ideas and principles about mathematics will emerge when teachers begin seeing the positive shifts and results of Project Maths.

\section{Next Step for Project Maths}

The professional development efforts of Project Maths to date have laid the foundation for change and provided a common experience around which teachers can engage in professional dialogue, reflection and collaboration. Teachers have begun making shifts in their thinking regarding the teaching and learning of mathematics but remain largely concerned with details of the shift (e.g. syllabuses, exams, time, etc.) rather than focusing on the impact of instructional shifts on student learning. Fullan [7], in examining the effectiveness of several models for change, discusses several premises that must be met in order to support the change process. The most relevant for considering change in Ireland include capacity building with a focus on results, learning in context, and reflective action. Capacity building, or "... any strategy that increases the collective effectiveness of a group to raise the bar and close the gap of student learning," [7, p. 9] includes an emphasis on positive pressure that motivates and provides resources to support and encourage growth. By providing continued positive pressure for change and leveraging the resources and collective professionalism of Irish teachers through continued, localized support, national educational leaders can build capacity for Project Maths and promote and capitalize on internal accountability. Learning in context, a second premise, "... actually changes the very context itself," [7, p. 9]. By allowing teachers to engage in continuous and sustained learning in the classroom setting, the norms and structures of what is means to do mathematics and the culture of mathematics teaching and learning will change. Finally, reflective action includes purposeful thinking about what teachers do in the classroom and why they are doing it. Teachers will learn best and rethink their approaches to mathematics by "... doing, reflection, inquiry, evidence, more doing and so on." [7, p. 10] 
When thinking about capacity building, learning in context, and reflective action as the "next steps" for Project Maths to further support and promote teacher change, there are three areas that stand out as particularly relevant. Though I am sure there are several more areas for growth that need to be considered by the Project Maths development team and other project leaders in determining where to go next with Project Maths, I was continually drawn to the need to clarify the message of Project Maths, provide continued and sustained site-based support, and stay the course.

\subsection{Clarify the Project Maths Message. As part of capacity} building and promoting ownership of Project Maths for students, parents, teachers, principals, and leaders alike, I feel Project Maths needs to clarify its message on two different fronts.

First, parents and students need a clearer message regarding the why of Project Maths [4, 5]. Although not a problem in the early days of Project Maths [15], there is now a small but loud faction of dissenters that is promoting "crisis rhetoric" that can potentially undermine current gains and inhibit future progress. Actively engaging in public dialogue about the research-based rationale behind Project Maths will help students, parents, and the general public better understand the intent and potential outcomes of Project Maths. Messages on project websites and research-based publications have not been sufficient to help inform parents and students of the various aspects of and connections between Project Maths, national assessments, and lifelong learning. Note that this is not encouragement to provide fodder for dissenters or engage in public debates to no avail. Rather, it is an opportunity to build upon a message that has been started but not fully developed or widely distributed.

In hindsight, we should have explained to parents that teaching under Project Maths was going to be different. There would be some disruption. Explain to them why the changes are taking place, what it will look like on their side of things. Engage with them and students to explain why, what and how to take the pressure off teachers. Give them rationale and understanding so they know teachers are being supported through these changes. -Michael, Project Maths program leader 
Second, teachers need to understand that Project Maths is promoting both pedagogical balance and incremental change. Although the Project Maths professional development team has done a very good job of sending a message of balanced pedagogy to Irish teachers through their day and evening courses, teachers largely view Project Maths as a huge and insurmountable pedagogical leap from their current practices. They interpret Project Maths as a complete departure from their more traditional approaches, rather than a "combined approach" [9] that incorporates reform-oriented approaches to mathematics along with appropriate aspects of more traditional instruction.

Project Maths is very good at sending the message of using appropriate strategies for your students but teachers leave the training sessions with the message that all math needs to be hands-on exploration. They see the alternative approaches and get a message that this is the way our teaching should always be. Teachers can be their own worst enemies. If a mix needs to be stipulated then we should tell them, even though teachers should know at the end of the day that mixed methodology is most appropriate. -Cian, maths teacher $\&$ department chair

Likewise, teachers need to understand that change takes time. Though Project Maths may be promoting large shifts in instruction, it will take a series of small changes to get there. This is one message that was seldom heard during my time in Ireland.

Teachers see a huge gap of what Project Maths wants and what teachers are doing. A message of incremental change is not getting out. - Andrew, Project Maths program leader

Through a concerted effort by Project Maths to continue sending a message of balanced pedagogical approaches and instructional decision making, along with continued support that promotes reflective action at the school-level and incremental change, teachers will begin to understand and act upon the take-away message of Project Maths: 
There is a balance between skills and procedures and application. We've historically been skills and procedures in this country. We are trying to find that balance. We need to help teachers rethink what we're teaching and how we're teaching it. But, I think teachers are thinking that we're going too far in the other direction than we're really going. It's all about finding that balance. - Megan, Project Maths leadership team

6.2. School-Level Support. As has been mentioned previously, Project Maths professional development efforts up to this point have laid the foundation for teachers to strengthen their content knowledge and begin thinking of teaching and learning mathematics in different ways. However, direct transfer and impact on teacher practice has been minimal. When asked which factors will promote actual classroom change, the overwhelming responses from teachers, leaders, administrators and Project Maths team members were: (1) school-level teamwork, collaboration, and communication and (2) strong local leadership interested in driving change. Interestingly enough, these are school-level factors that cannot be taught in a workshop but must be cultivated in context through reflective practice, collaboration, and access to additional resources, skills, and knowledge. This recommendation echoes findings of previous researchers in highlighting the importance of contextualized, resourcerich continued professional development [4, 5].

Two examples of self-sustaining initiatives that could be used effectively at a school-level in order to promote reflective action and learning in context are Lesson Study and Communities of Practice. Communities of practice [24] include small groups of teachers who are committed to continuous improvement of their craft by engaging in collective inquiry, collaboration and reflection into best practice. Communities of practice often focus on student learning, rather than instruction, to collectively undertake activities and reflection in order to improve student performance. Lesson study [13], a more refined focus on the impact of a single lesson on student learning, is a professional development strategy that can be used in conjunction with communities of practice or on its own. The process involves a small group of teachers examining their practice in depth and in the context of student learning by collaborating on, implementing, revising, and collectively reflecting on a jointly planned research 
lesson. Both of these approaches to promoting authentic teacher engagement in their own change have been proven successful at pilot schools in Ireland and provide a context for national schools to put Project Maths theory, content, and pedagogy into action. The skills and capacity needed to successfully implement these initiatives can be initiated and supported through the existing national structure of regional centers, regional development officers, and the Irish Maths Teachers Association. While an initial influx of funding will be necessary to train teachers in the use of such tools, professional development can be done within the national structure for support already in place. A primary example of building the infrastructure to support these self-sustaining initiatives is the recent "Math Counts: Insights into Lesson Study" conference held in Maynooth in November 2013 (http://projectmaths.ie/conferences/maths-counts.asp).

Along with new tools that promote classroom level collaboration and reflective practice, whole school shifts in prioritizing communication around practice need to occur. This is where strong leadership will play a role in determining the scope and direction of school wide change.

School leaders play a big part in helping teachers adapt. Principals need to be flexible to deal with the messiness of things like timetables, flexibility in scheduling and the like. Schools where principals are not as supportive have struggled. - Michael, Project Maths program leader

As one inspectorate put it after observing many national roll-out schools, "Schools with strong leadership that are supporting a culture shift are doing better than those lacking leadership." Schools where the principal supports change and encourages the type of reflective practice that enables teachers to act as change agents will be more successful at truly adopting Project Maths. It is the school principal that will set the tone for change at a school and provide the structure and support, through explicit meeting times and positive pressure with a focus on results, for teachers and departments to spend dedicated time, energy, and resources in content area groups.

We have informal meetings at grade level, but there are very few organized maths department meetings. Whole school meetings focus on policies and procedures with pedagogy at the bottom. But, that should be switched so 
that pedagogy is discussed more and just tell us the new restroom policy. - Cian, maths teacher $\&$ department chair

Timetabling and variations in contracts and hours often inhibit this, but schools need to find a way, perhaps through the use of Croke Park hours or other redistribution of contract hours, to enable teachers to meet as professionals and engage in the dialogue of their craft.

6.3. Stay the Course. Long term, meaningful change must be cultivated over time. It is often bumpy, messy and nonlinear in its progression. A strong resolve to stay the course with flexibility is paramount. "Failure to keep going in the face of inevitable barriers achieves nothing," [7, p. 11]. Project Maths is a research-validated approach to teaching and learning mathematics that needs further time and classroom-based support in order to realize its intended impact on student achievement and understanding in mathematics. If there is no follow up at a localized level to support teachers through contextualized learning, reflective action, and positive pressure that motivates, teachers will simply hold strong to their established practices. Teachers need school-based support to move past their initial self-focused concerns and worries into thinking about impact on student learning (beyond cert performance).

We need to hold the line. We need to keep moving forward with continued professional development. We need to make sure new teachers are coming in and moving up. We need to keep a focus on training our out-of-field teachers. We need to keep the RDO structure in place. We need a self-sustaining structure that might be supported by communities of practice. The departmental structure at secondary schools is not strong; we need to improve this. We can't just fall off into nothing. -Andrew, Project Maths program leader

The teachers of Ireland care about their students and their craft. They are trying to engage in Project Maths in authentic ways, but need continued school-based support in order to deal with the structural barriers and internal factors that are hindering their continued growth. They need a structure in which to engage with one another in professional dialogue and reflective practice. They need 
to understand that small change is better than no change at all and stumbling along the way is an inevitable part of the change process. They need the support of their colleagues to try things, fail at them, share their experiences and try again.

The content is the content, and now we're being asked to rethink the pedagogy. I've been trying to do this all along. I think we're heading in the right direction but many teachers just need help in getting there. - Cian, maths teacher $\&$ department chair

In the end, "... you can't change teachers, you have to get them engaged in their own change," (Megan, Project Maths leadership team).

\section{Implications for Common Core CPD}

It is hard to compare the professional development efforts in Ireland with any past or current programs in the United States. While we in the US are certainly edging toward a near-national curriculum with Common Core, we are nowhere near having a centrally developed, funded, or implemented professional development plan to support implementation of Common Core. Helping teachers adapt to and adopt the content and pedagogy of Common Core is left to states and largely dependent upon state and local funding and existing professional development initiatives and structures. As with Ireland, there is a general expectation that once statewide assessments tied to Common Core change to reflect content and pedagogical shifts associated with Common Core, teachers will be left with no alternative other than to adopt the instruction and problem solving approaches inherent in Common Core. While the stakes associated with testing in the United States are directed more towards teachers and schools than students themselves, graduation from secondary school is often tied to students' performance and scores on such exams. In the meantime, teachers need support in interpreting and applying the new problem-solving, student-centred pedagogical and content-based approach of Common Core.

The prevailing model of professional development associated with most intensive Common Core-related projects is similar to that used by Project Maths. Professional development focuses on improving teachers' content knowledge through engagement in an intensive professional development program that includes one or two weeks 
of instruction during the summer and several weekends of follow up instruction during the academic year. Instruction is based largely on increasing teachers' content knowledge through modeling and engagement with content, explicit discussions centred around pedagogical decision making, and additional instruction in areas of assessment, student engagement, differentiation, and other related skills and knowledge. Communities of practice have long played a role in professional development, but one of the lessons learned from my time in Ireland is the absolute importance of longer term support at the school-level. While this one year intensive approach to Common Core appears to be successful, at least in the short term, there is no true measure of longer term gains related to changing classroom instruction and sustained teacher growth.

Like Project Maths, my work values the intensive content-based professional development workshops in laying the foundation for change. This initial experience provides teachers with the content and context around which to begin thinking about change. In and of itself, however, it has very little impact on teacher practice or student learning experiences. Like teachers in Ireland, teachers in Arizona struggle with issues of change and the resulting lack of confidence in their own content knowledge, the pedagogical shifts involved in a more student-centred problem based approach to mathematics instruction, and how those changes will be reflected in statewide assessments. True change will occur with longer term support that is focused on the context of the classroom and provides teachers with explicit experiences and expectations to engage in collaborative reflective practice. "Change is primarily an experientially based learning process for teachers..." [10, p. 384].

As Guskey noted, "Of all aspects of professional development, sustaining change is perhaps the most neglected," [10, p. 388]. Since change occurs after, during and throughout implementation, support coupled with positive pressure is needed for continued educational improvement. If Project Maths, or Common Core, is to be implemented well by teachers, the shifts in content and pedagogy must become part of teachers' instructional repertoire and used out of habit rather than conscious thought. Because change is a process rather than a single event, long term commitment to change and continued support are essential. "Support allows those engaged 
in the difficult process of implementation to tolerate the anxiety of occasional failure," [10, p. 388].

Project Maths and Common Core are both initiatives that are focused on changing teaching, changing learning, and changing the mathematics culture of students, parents, and teachers alike. As Fullan [7] indicated, such wide scale reform is not just putting into place new policy, but changing the culture of classrooms, schools, districts and, in the case of Project Maths, a country.

\section{ACKNOWLEDGEMEnts}

I would like to thank CASTeL for hosting my stay in Ireland and making my visit possible. I am particularly grateful to Maurice O'Reilly (St. Patricks, Drumcondra) and Brien Nolan and Eabhnat Ní Fhloinn (DCU) for enculturating me to the Irish mathematics education system and for introducing me to the many players in the mathematics education field in Ireland. I would especially like to thank secondary Irish maths teachers for allowing me into their classrooms and training sessions, and for their candidness, openness and obvious love of teaching. I am grateful to all the leaders of Project Maths who took time out of their busy schedules to meet with me to openly share their thoughts, including the good and the bad. Their own frankly honest reflections on Project Maths were invaluable. I look forward to watching the continued professional development efforts of Project Maths and to the continued growth of mathematics teachers across Ireland.

\section{REFERENCES}

[1] Aysel, Tugba. (2012). An Exploration of the Effects of High-Stakes Examinations on the Teahcing and Learning of Mathematics in Post-Primary Education in Ireland and Turkey. PhD thesis, National University of Ireland Maynooth. Retrieved from http://eprints.nuim.ie/4034/.

[2] Common Core State Standards Initiative: Preparing America's Students for College \& Career (CCSSI). (2012). Retrieved from http://www . corestandards.org/

[3] Common Core State Standards Mathematics (CCSSM). (2012). Retrieved from http://www . corestandards.org/Math

[4] Cosgrove, J., Perkins, R., Shiel, G., Fish, R., \& McGuinness, L. (2012). Teaching and Learning in Project Maths: Insights from Teachers Who Participated in PISA 2012. Dublin: Educational Research Center.

[5] Department of Education and Skills (2010). Report of the Project Maths Implementation Support Group. Dublin: DES. 
[6] Duffy, G.G. (1993). Teachers' progress toward becoming expert strategy teachers. The Elementary School Journal, 94, 109 - 120.

[7] Fullan, M. (2006). Change theory: A force for school improvement. Melbourne, AU: Seminar Series Paper 157, Centre for Strategic Education.

[8] Fullan, M. \& Stiegelbauer, S.M. (1991). The new meaning of educational change. New York: Teachers College Press.

[9] Grannell, J.J., Barry, P.D., Cronin, M., Holland, F., \& Hurley, D., (2011). Interim report on Project Maths. Cork: School of Mathematical Sciences, University College Cork.

[10] Guskey, T.R. (2002). Professional Development and Teacher Change. Teachers and Teaching: Theory and Practice, 8(3/4), $381-391$.

[11] Hord, S.M., Rutherford, W.L., Huling-Austin, L., \& Hall, G.E. (1987). Taking charge of change. Austin, TX: Southwest Educational Development Laboratory.

[12] Jeffe, J., Jones, E., Cunningham, R., Dawson, A., Cooper, L., Straw, S., Sturman, L., \& O'Kane, M. (2012). First interim report for the Department of Education and Skills and the National Council for Curriculum and Assessment: Research into the impact of Project Maths on student achievement, learning and motivation. Berkshire, England: National Foundation for Education Research.

[13] Lewis, C. (2002). Lesson study: A handbook of teacher-led instructional change. Philadelphia: Research for Better Schools.

[14] Loucks-Horsley, S. (1996). Professional development for science education: A critical and immediate challenge. From Bybee, R. (Ed.) National Standards $\&$ the Science Curriculum. Dubuque, Iowa: Kendall/Hunt.

[15] Lubienski, S. (2011). Mathematics Education and Reform in Ireland: An Outsider's Analysis of Project Maths. Irish Mathematical Society Bulletin, $67,27-55$.

[16] Madinach, E., \& Cline, H. (1992). The impact of technological curriculum innovation on teaching and learning activities. Paper presented at the American Educational Research Association Conference, San Francisco, CA.

[17] Marzano, R.J., Zaffrom, S., Zraik, L., Robbins, S.L., \& Yoon, L. (1995). A New Paradigm for Educational Change. Education, 116(2), 162-173.

[18] O'Keefe \& O'Donoghue. (2011). A Review of School Textbooks for Project Maths. Limerick: National Centre for Excellence in Mathematics and Science Teaching and Learning, University of Limerick.

[19] National Council for Curriculum and Assessment/Department of Education and Skills (2012). Project Maths: Reviewing the Project in the Initial Group of 24 Schools - Report on School Visits. Dublin: NCCA/DES.

[20] National Council for Curriculum and Assessment (NCCA). (2013) Project Maths. http://www.ncca.ie/en/Curriculum_and_Assessment/ Post-Primary_Education/Project_Maths/

[21] Race to the Top Fund. (2009). Retrieved from http://www2.ed.gov/ programs/racetothetop/index.html.

[22] Ní Riordain, M., \& Hannigan, A. (2009). Out-of-field teaching in post-primary mathematics education: An analysis of the Irish Context. Limerick: National Centre for Excellence in Mathematics and Science Teaching and Learning, University of Limerick. 
[23] United States Department of Education (USDOE). (2010). Public Law print of PL 10\%-110, the No Child Left Behind Act of 2001. Retrieved from http: //www.ed.gov/policy/elsec/leg/esea02/index.html

[24] Wegner-Trayner, E. (2006). Communities of practice: A brief introduction. Retrieved from http://wenger-trayner.com/theory/.

Shannon Guerrero is an Associate Professor of Mathematics Education at Northern Arizona University. She teaches undergraduate and graduate mathematics content and pedagogy courses within the Department of Mathematics and Statistics. Her research interests include K-12 pre-service and in-service professional development, the effective use of technology in support of standards-based mathematics teaching and learning, and the process of teacher change. She lives in Flagstaff, Arizona, USA, with her husband and three children

Northern Arizona University, Department of Mathematics \& StaTistics, PO Box 5717, FlagstafF, AZ 86011, USA

E-mail address: Shannon.Guerrero@nau.edu 